\title{
Correction to: Teaching interrelated concepts of fraction for understanding and teacher's pedagogical content knowledge
}

\section{Seyum Getenet ${ }^{1}$ (D) $\cdot$ Rosemary Callingham ${ }^{2}$}

Published online: 27 July 2019

(C) Mathematics Education Research Group of Australasia, Inc. 2019

\section{Correction to: Mathematics Education Research Journal https://doi.org/10.1007/s13394-019-00275-0}

The original version of this article unfortunately contained a mistake. The figures in Fig. 2 and Fig. 3 are misplaced. The figure in Fig. 3 is "An example of representing the measure construct of fraction (Siemon et al. 2015)" and should be placed in Fig.2, whereas, the figure in Fig. 2 represents "The operator construct of fraction (Getenet and Callingham 2017)" and should be placed in Fig. 3. The correct versions are given below.

The original article has been corrected.

Publisher's note Springer Nature remains neutral with regard to jurisdictional claims in published maps and institutional affiliations.

The online version of the original article can be found at https://doi.org/10.1007/s13394-019-00275-0

Seyum Getenet

Seyum.Getenet@usq.edu.au

Rosemary Callingham

Rosemary.Callingham@utas.edu.au

1 University of Southern Queensland, Toowoomba, Australia

2 University of Tasmania, Hobart, Australia 


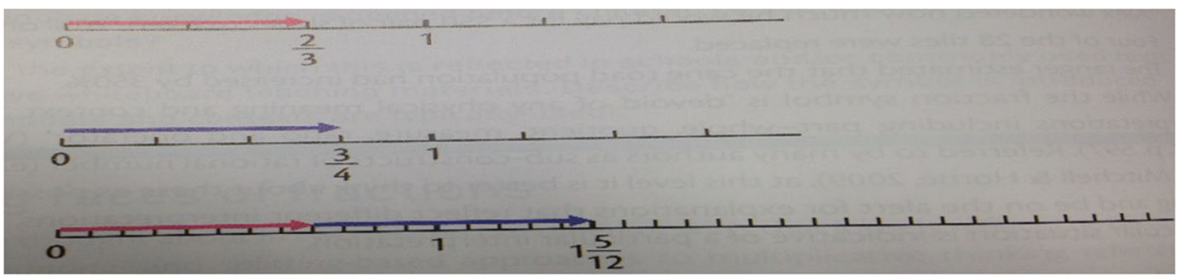

Fig. 2 An example of representing the measure construct of fraction (Siemon et al., 2015)

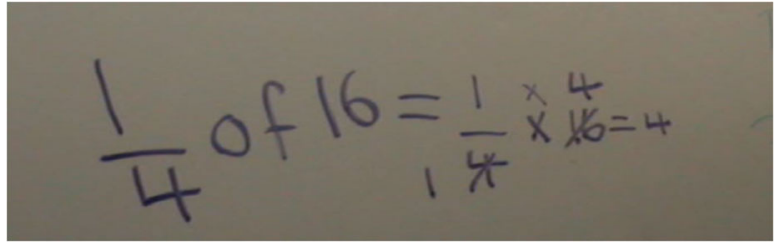

Fig. 3 The operator construct of fraction (Getenet \& Callingham, 2017) 